\title{
Sciatica-Related Spinal Imbalance in Lumbar Disc Herniation Patients: Radiological Characteristics and Recovery Following Endoscopic Discectomy
}

\section{Liang Wang* \\ Chao Li* \\ Lianlei Wang \\ Lei Qi \\ Xinyu Liu}

Department of Orthopaedic Surgery, Qilu Hospital of Shandong University, Jinan, Shandong, People's Republic of China

*These authors contributed equally to this work
Correspondence: Lei Qi; Xinyu Liu Tel +86-53I-82I 65995

Fax +86-53I-82I 65993

Email qilei_spine@hotmail.com;

newyuliu@।63.com
Background: Sciatica-related spinal imbalance could be observed in lumbar disc herniation (LDH) patients. However, their characteristics and recovery process remained unclear. The purpose was to analyze the radiological characteristics of spinal imbalance related to sciatica and recovery following endoscopic discectomy.

Methods: The records of LDH patients with sciatica and spinal imbalance receiving endoscopic discectomy were retrospectively reviewed. The patients were divided to Group A (sagittal imbalance), Group B (coronal imbalance) and Group C (sagittal and coronal imbalance). The whole-spine x-ray was performed at pre-operation, immediately postoperation, 3-month and 6-month follow-up and related radiological parameters were measured.

Results: A total of $110 \mathrm{LDH}$ patients (18.3\%) presented with spinal imbalance were included and there were 31 patients in Group A, 38 patients in Group B and 41 patients in Group C. In this study, $77.2 \%$ of the coronal imbalance patients present with trunk shifted to contralateral side of disc herniation and $65.3 \%$ of the sagittal imbalance patients present with forward trunk. Most patients present mild and moderate sagittal and coronal imbalance. The magnitude of sagittal and coronal imbalance in Group $\mathrm{C}$ was significantly more severe than that of Group A and Group B. Most patients $(\geq 75 \%)$ acquired spinal balance immediately after surgery. The sagittal imbalance improved better than coronal imbalance and single plane imbalance improved better than biplane imbalance. At the postoperative 6-month follow-up, all patients recovered to normal sagittal and coronal balance.

Conclusion: Sciatica-related spinal imbalance occurs in $18.3 \%$ of the LDH patients receiving endoscopic discectomy. Different subgroups of spinal imbalance present different characteristics. Spontaneous correction of the spinal imbalance could be achieved when sciatica was relieved immediately after surgery and well maintained during follow-up.

Keywords: sciatica, lumbar disc herniation, spinal imbalance, radiological characteristics, recovery, endoscopic discectomy

\section{Introduction}

Lumbar disc herniation (LDH) is an increasingly common disease in the world, and sciatica is the most common related symptom. ${ }^{1-3}$ Based on population studies, the incidence of symptomatic LDH accounts for an appropriate $1 \%$ of the general population. ${ }^{4}$ The main symptoms of most LDH patients are low back pain with sciatica and difficulty in walking. 5,6 
However, coronal and sagittal trunk tilt, even spinal imbalance, could be caused by sciatica in some LDH patients, which is thought to be compensatory for nerve root stimulation caused by disc herniation. ${ }^{7,8}$ Meanwhile, spinal coronal and sagittal imbalance related to sciatica in these LDH patients lead to abnormal trunk tilt appearance, especially when sitting, standing, and walking. ${ }^{9}$ The trunk tilt appearance could cause great distress to the patients and influence the doctor's diagnosis. In addition to pain relief, patients worry about whether and when the trunk tilt could recover. Related studies have shown that spinal imbalance caused by sciatica and LDH is nonstructural and could improve with the relief of pain. ${ }^{10,11}$

To our knowledge, the studies focused on sciatica related spinal imbalance in LDH were limited and most of them just concentrated on single sagittal or coronal spinal imbalance. Here, we divided the LDH patients with spinal imbalance into different subgroups and analyze their different characteristics and the recovery following endoscopic discectomy.

\section{Methods}

The study was approved by the ethics committee of Qilu Hospital of Shandong University (No. KYLL-2019KS-058) and performed in accordance with the Helsinki Declaration. Written informed consent was obtained from all patients before enrollment. We retrospectively reviewed the records of LDH patients with single level involved and unilateral sciatica who underwent endoscopic discectomy from January 2016 to January 2021 in our single institution. Exclusion criteria include LDH involved levels other than L3-S1, multi-level LDH, previous lumbar spinal surgery, lumbar spinal stenosis, spondylolisthesis, instability, idiopathic or congenital and other structural spinal deformity. LDH diagnosis criteria are based on the clinical neurological symptoms and radiological manifestation, including CT and MRI. Endoscopic discectomy surgeries include posterior endoscopic transforaminal discectomy (PETD), posterior endoscopic interlaminar discectomy (PEID), unilateral biportal endoscopic discectomy (UBED) and microendoscopic discectomy (MED).

\section{Radiological Measurements}

Radiological measurements were made on standing anteroposterior (A-P) and lateral X-ray of the entire spine at pre-operation, immediately post-operation, and postoperative 3-month and 6-month follow-up (Figure 1). The horizontal distance from the central sacral vertical line
(CSVL) to $\mathrm{C} 7$ plumb line (C7PL) on A-P X-ray was measured to assess coronal imbalance (CSVL-C7PL). The sagittal vertical axis (SVA) was measured by the distance between C7PL and the S1 posterior-superior corner on lateral X-ray, which was used to assess sagittal imbalance. The difference of bilateral shoulder height was measured on the A-P X-ray.

The coronal imbalance was defined as CSVL-C7PL $\geq 20 \mathrm{~mm} .{ }^{12}$ The coronal imbalance was graded to mild (20 $\mathrm{mm} \leq$ CSVL-C7PL $<40 \mathrm{~mm})$, moderate $(40 \mathrm{~mm} \leq$ CSVL-C7PL $<60 \mathrm{~mm}$ ) and severe (CSVL-C7PL $\geq 60 \mathrm{~mm}$ ). The sagittal imbalance was defined as SVA $\geq 40 \mathrm{~mm}$. ${ }^{13}$ It was graded to mild imbalance $(40 \mathrm{~mm}<\mathrm{SVA} \leq 60 \mathrm{~mm}$ ), moderate imbalance $(60 \mathrm{~mm}<\mathrm{SVA} \leq 80 \mathrm{~mm})$ and severe imbalance (SVA $>80 \mathrm{~mm}$ ).

\section{Subgroups}

Based on the types of imbalance, these LDH patients with spinal imbalance were divided into three subgroups:
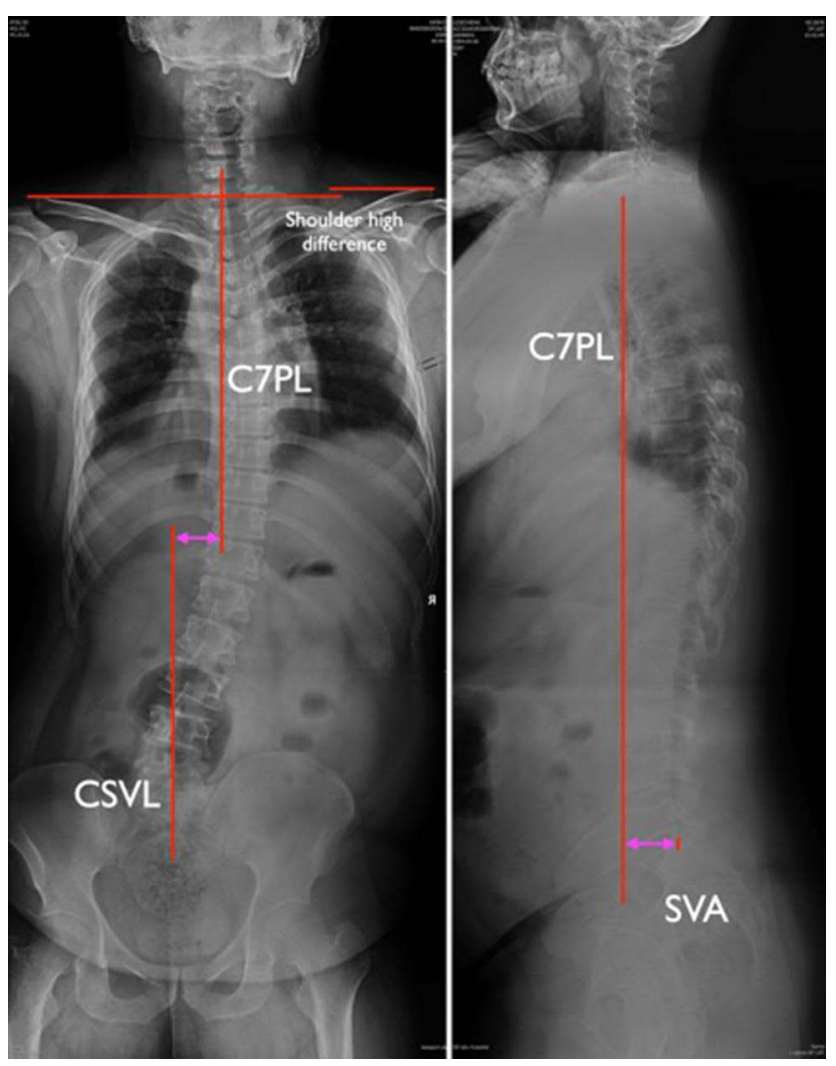

Figure I Radiological measurements. Radiological measurements were made on standing anteroposterior (A-P) and lateral $X$-ray of the entire spine. The horizontal distance of CSVL-C7PL on A-P X-ray was measured to assess coronal imbalance. The SVA was measured by the distance between C7PL and the SI posteriorsuperior corner on lateral $X$-ray, which was used to assess sagittal imbalance. The bilateral shoulder height difference was measured on the A-P X-ray. 
Group A (sagittal imbalance), Group B (coronal imbalance), and Group C (sagittal and coronal imbalance).

\section{Statistical Analysis}

All continuous data were expressed as the mean \pm standard deviation. One-way analysis of variance (ANOVA) was performed to analyze the differences of radiological parameters among Group A, Group B and Group C. Differences between preoperative and postoperative parameters were determined by the independent-sample $T$ test. The chi-square test was performed to analyze the categorical variables. $\mathrm{P}<0.05$ was considered as statistically significant. Statistical measures were performed using Statistical Package for Social Science (SPSS, 19.0).

\section{Results}

\section{Patients Population}

There were 600 records of the LDH patients with single level involved and unilateral sciatica who underwent endoscopic discectomy meeting the including criteria. A total of 110 patients (54 male and 56 female) were verified with spinal imbalance and the incidence of spinal imbalance in LDH was $18.3 \%$ in the current study. The characteristics of these patients are summarized in Table 1. All patients gained sciatica relief immediately after endoscopic discectomy. The preoperative and postoperative mean visual analogue scale/score for leg pain (VAS-Leg) was $8.4 \pm 3.1$ and $2.2 \pm 1.5$, respectively $(\mathrm{P}<0.05)$. There was no significant correlation between the preoperative VAS and severity of spinal imbalance $(\mathrm{P}>0.05)$.

Among the 110 patients, there were 31 patients in Group A, 38 patients in Group B and 41 patients in Group C. There were no significant differences in age, sex, BMI, bilateral shoulder height and LDH level for the three subgroups (Table 2).

\section{Radiological Measurement and Subgroup Analysis}

As for the sagittal imbalance direction, 65.3\% (47/72) patients present sagittal forward trunk tilt, including 14 patients in Group A and 33 patients in Group C. The direction of coronal imbalance was not consistent with the symptomatic side in $77.2 \%(61 / 79)$ patients, including 31 patients in Group B and 30 patients in Group C.

The sagittal imbalance of SVA was $66.0 \pm 19.5 \mathrm{~mm}$ in Group $\mathrm{A}$ and $83.5 \pm 40.7 \mathrm{~mm}$ in Group $\mathrm{C}(\mathrm{P}<0.05)$. In Group A, most patients (87.1\%) present mild and
Table I Demographic and Clinical Characteristics for All the Cases

\begin{tabular}{|l|c|}
\hline & All the Cases \\
\hline Number of cases $(\mathrm{n})$ & $\mathrm{I} 10$ \\
\hline Sex (male/female) & $54 / 56$ \\
\hline Age (years) & $42.05 \pm 14.82$ \\
\hline BMI (kg/m ${ }^{2}$ ) & $25.64 \pm 3.69$ \\
\hline Bilateral shoulder height difference $(\mathrm{mm})$ & $8.83 \pm 7.56$ \\
\hline LDH level (case number) & \\
L3/4 & 4 \\
L4/5 & 61 \\
L5/SI & 45 \\
\hline Surgical methods (case number) & 33 \\
PEID & 39 \\
PETD & 28 \\
UBED & 10 \\
MED & \\
\hline VAS-leg for sciatica & $8.4 \pm 3.1^{*}$ \\
Preoperative & $2.2 \pm 1.5^{*}$ \\
Postoperative & \\
\hline
\end{tabular}

Notes: *Significant difference between preoperative and postoperative VAS-leg for sciatica.

Abbreviations: LDH, lumbar disc herniation; PEID, posterior endoscopic interlaminar discectomy; PETD, posterior endoscopic transforaminal discectomy; UBED, unilateral biportal endoscopic discectomy; MED, microendoscopic discectomy.

moderate imbalance. In Group $\mathrm{C}$, the proportion of mild (31.7\%), moderate (34.1\%) and severe (34.1\%) was roughly equal. The coronal imbalance of CSVL-C7PL was $31.7 \pm 12.8 \mathrm{~mm}$ in Group $\mathrm{B}$ and $41.5 \pm 22.0 \mathrm{~mm}$ in Group $\mathrm{C}(\mathrm{P}<0.05)$. Most patients present mild coronal imbalance in both Group B (78.9\%) and Group C (63.4\%).

The immediately postoperative and follow-up results showed favorable recovery of spinal imbalance. There was significant correlation between the VAS relief and spinal imbalance recovery after surgery $(\mathrm{P}<0.05)$. In Group $\mathrm{A}$, all patients $(100 \%)$ acquired sagittal balance immediately after surgery. The SVA decreased from $66.0 \pm 19.5 \mathrm{~mm}$ to $24.3 \pm 9.2 \mathrm{~mm}$ with the improvement rate was $63.1 \%$. At the 3-month and 6-month follow-up, the SVA decreased to $18.5 \pm 8.8 \mathrm{~mm}$ and $15.1 \pm 7.3 \mathrm{~mm}$ with the average improvement rate of $72.0 \%$ and $77.1 \%$, respectively.

In Group B, $80 \%$ of the patients acquired coronal balance immediately after surgery. The CSVL-C7PL decreased from $31.7 \pm 12.8 \mathrm{~mm}$ to $13.6 \pm 5.7 \mathrm{~mm}$ with the improvement rate was $64.8 \%$. At the 3-month and 6-month follow-up, $89 \%$ and $100 \%$ of the patients acquired coronal 
Table 2 Characteristics and Recovery of Spinal Imbalance in Three Subgroups

\begin{tabular}{|c|c|c|c|c|}
\hline & Group A & Group B & \multicolumn{2}{|c|}{ Group C } \\
\hline Number of cases (n) & 31 (28.2\%) & $38(34.5 \%)$ & \multicolumn{2}{|c|}{$4 \mathrm{I}(37.3 \%)$} \\
\hline Sex (male/female) & $14 / 17$ & $16 / 22$ & \multicolumn{2}{|c|}{$24 / 17$} \\
\hline Age (years) & $44.3 \pm 15.8$ & $42.6 \pm 14.0$ & \multicolumn{2}{|c|}{$40.2 \pm 15.0$} \\
\hline BMI & $25.5 \pm 4.3$ & $25.1 \pm 2.9$ & \multicolumn{2}{|c|}{$26.3 \pm 3.9$} \\
\hline Level of LDH (L3/4: L4/5: L5/SI) & $1: 14: 16$ & $0: 25: 13$ & \multicolumn{2}{|c|}{$3: 22: 16$} \\
\hline Bilateral shoulder height difference $(\mathrm{mm})$ & $8.3 \pm 7.4$ & $8.3 \pm 6.4$ & \multicolumn{2}{|c|}{$9.7 \pm 8.7$} \\
\hline Side of LDH and symptom (left/right) & $17 / 14$ & $20 / 18$ & \multicolumn{2}{|c|}{$15 / 26$} \\
\hline Coronal imbalance direction (left/right) & - & $23 / 15$ & \multicolumn{2}{|c|}{$29 / 12$} \\
\hline $\begin{array}{l}\text { Number of cases of symptomatic side not consistent with coronal } \\
\text { imbalance direction }(n)\end{array}$ & - & 31 & \multicolumn{2}{|c|}{30} \\
\hline Sagittal imbalance direction (forward/backward) & $14 / 17$ & - & \multicolumn{2}{|c|}{$33 / 8$} \\
\hline $\begin{array}{l}\text { Coronal imbalance }(\mathrm{mm}) \\
\text { Grading (case number) } \\
\text { Mild ( } 20 \leq \mathrm{CSVL}-\mathrm{C} 7 \mathrm{PL}<40) \\
\text { Moderate }(40 \leq \mathrm{CSVL}-\mathrm{C} 7 \mathrm{PL}<60) \\
\text { Severe }(60 \leq \mathrm{CSVL}-\mathrm{C} 7 \mathrm{PL})\end{array}$ & - & $\begin{array}{c}31.7 \pm 12.8^{\#} \\
30(78.9 \%) \\
7(18.4 \%) \\
1(2.6 \%)\end{array}$ & & $\begin{array}{l}4 \%) \\
5 \%) \\
(\%)\end{array}$ \\
\hline $\begin{array}{l}\text { Sagittal imbalance }(\mathrm{mm}) \\
\text { Grading (case number) } \\
\text { Mild }(40 \leq \mathrm{SVA}<60) \\
\text { Moderate }(60 \leq \mathrm{SVA}<80) \\
\text { Severe }(80 \leq \mathrm{SVA})\end{array}$ & $\begin{array}{l}66.0 \pm 19.5 * \\
15(48.4 \%) \\
12(38.7 \%) \\
4(12.9 \%)\end{array}$ & - & & $\begin{array}{l}7 \%) \\
. \%) \\
. \%)\end{array}$ \\
\hline Follow-up & SVA & CSVL-C7PL & SVA & CSVL-C7PL \\
\hline Immediately (mm) & $24.3 \pm 9.2$ & $13.6 \pm 5.7$ & $33.5 \pm 17.2$ & $16.1 \pm 7.9$ \\
\hline Percentage of recovery & $100 \%$ & $80 \%$ & $80 \%$ & $75 \%$ \\
\hline Improvement rate & $63.1 \%$ & $57.2 \%$ & $59.9 \%$ & $61.2 \%$ \\
\hline 3-month (mm) & $18.5 \pm 8.8$ & $9.8 \pm 5.3$ & $31.7 \pm 8.2$ & $11.5 \pm 7.7$ \\
\hline Percentage of recovery & $100 \%$ & $89 \%$ & $100 \%$ & $83 \%$ \\
\hline Improvement rate & $72.0 \%$ & $69.2 \%$ & $62.1 \%$ & $71.5 \%$ \\
\hline 6-month (mm) & $15.1 \pm 7.3$ & $7.4 \pm 5.0$ & $20.8 \pm 7.9$ & $8.8 \pm 6.9$ \\
\hline Percentage of recovery & $100 \%$ & $100 \%$ & $100 \%$ & $100 \%$ \\
\hline Improvement rate & $77.1 \%$ & $76.6 \%$ & $75.1 \%$ & $78.7 \%$ \\
\hline
\end{tabular}

Notes: * * Significant difference between different subgroups.

Abbreviations: LDH, lumbar disc herniation; CSVL, central sacral vertical line; C7PL, C7 plumb line; SVA, sagittal vertical axis.

balance, respectively. The CSVL-C7PL decreased to 9.8 $\pm 5.3 \mathrm{~mm}$ and $7.4 \pm 5.0 \mathrm{~mm}$ with the improvement rate of $69.2 \%$ and $76.6 \%$, respectively.

In Group C, $80 \%$ and $75 \%$ of the patients acquired sagittal and coronal balance immediately after surgery. The SVA decreased from $83.5 \pm 40.7 \mathrm{~mm}$ to 33.5 $\pm 17.2 \mathrm{~mm}$ with the improvement rate of $59.9 \%$. The CSVL-C7PL decreased from $41.5 \pm 22.1 \mathrm{~mm}$ to 16.1 $\pm 7.9 \mathrm{~mm}$ with the improvement rate of $61.2 \%$. At the 3-month and 6-month follow-up, all patients acquired sagittal balance. The SVA decreased to $31.7 \pm 8.2 \mathrm{~mm}$ and $20.8 \pm 7.9 \mathrm{~mm}$ with the improvement rate of $62.1 \%$ and $75.1 \%$, respectively. Moreover, $83 \%$ and $100 \%$ of the patients acquired coronal balance at 3-month and 6-month. The CSVL-C7PL decreased to $11.5 \pm 7.7 \mathrm{~mm}$ and $8.8 \pm 6.9 \mathrm{~mm}$ with the improvement rate of $71.5 \%$ and $78.7 \%$, respectively. Three cases of LDH with spinal imbalance were shown in Figures 2-4. 

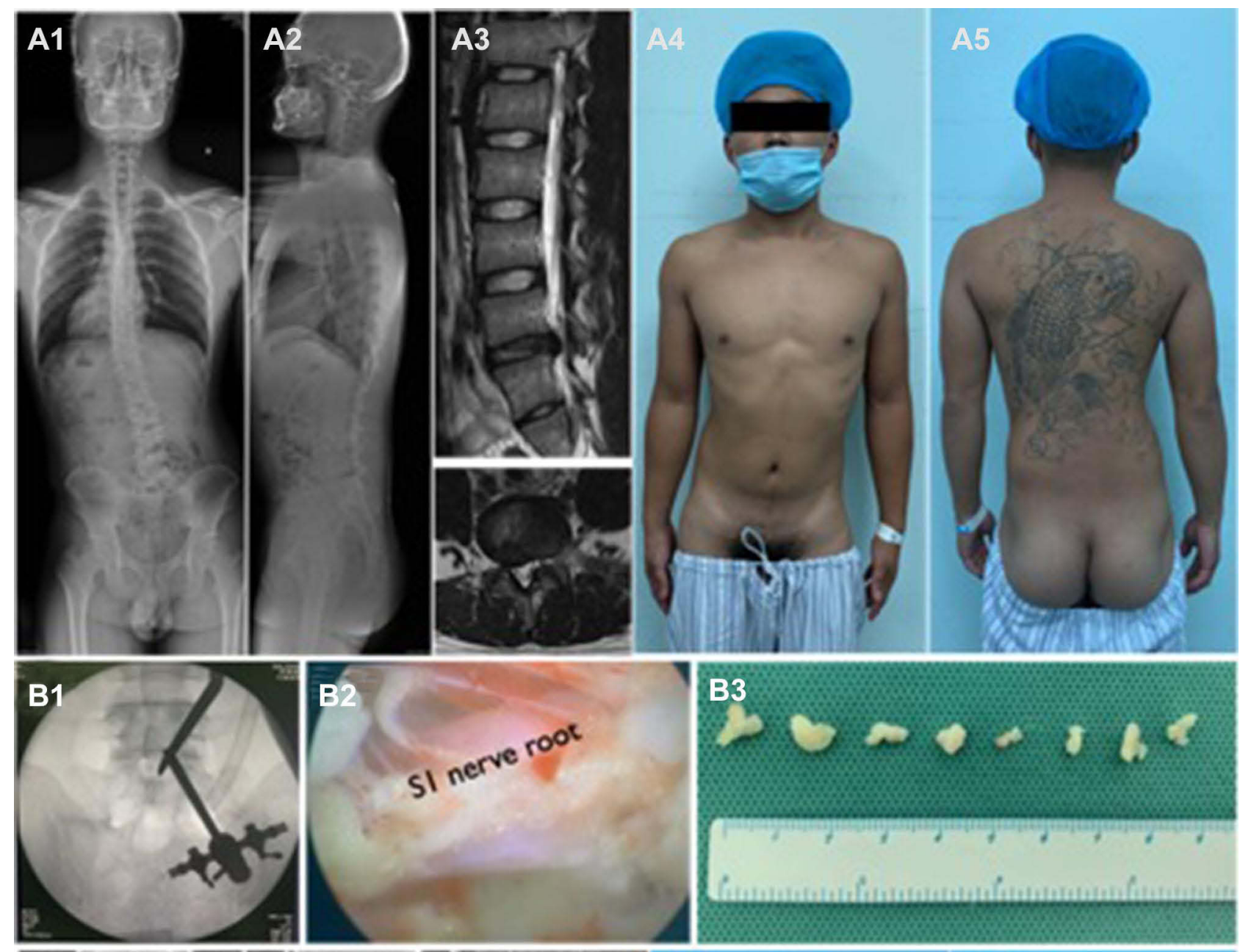

83
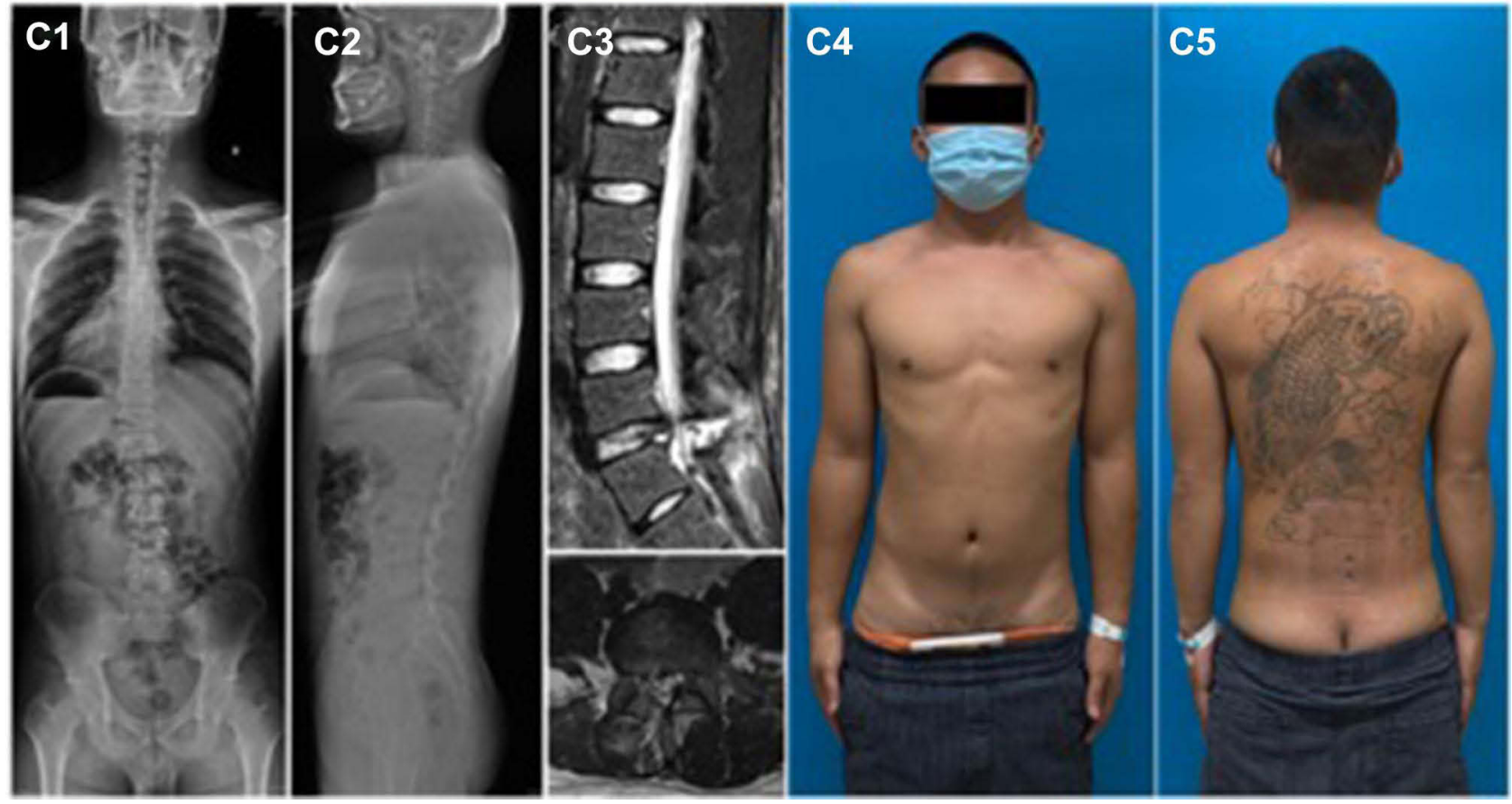

Figure 2 A 24-year-old male LDH patient with right leg sciatica present spinal coronal imbalance (AI-2). L5/SI right side disc herniation was shown in MRI (A3). X-ray (AI2) and physical appearance (A4-5) showed the trunk shifted to left side in coronal plane. UBED surgery was performed (B I-3) and postoperative MRI showed herniated disc was removed (C3). X-ray (CI-2) and physical appearance (C4-5) showed coronal imbalance acquired recovery immediately after surgery. (As it is possible the patient could be identified by the tattoo on his back, he has provided informed consent for the images to be published.). 

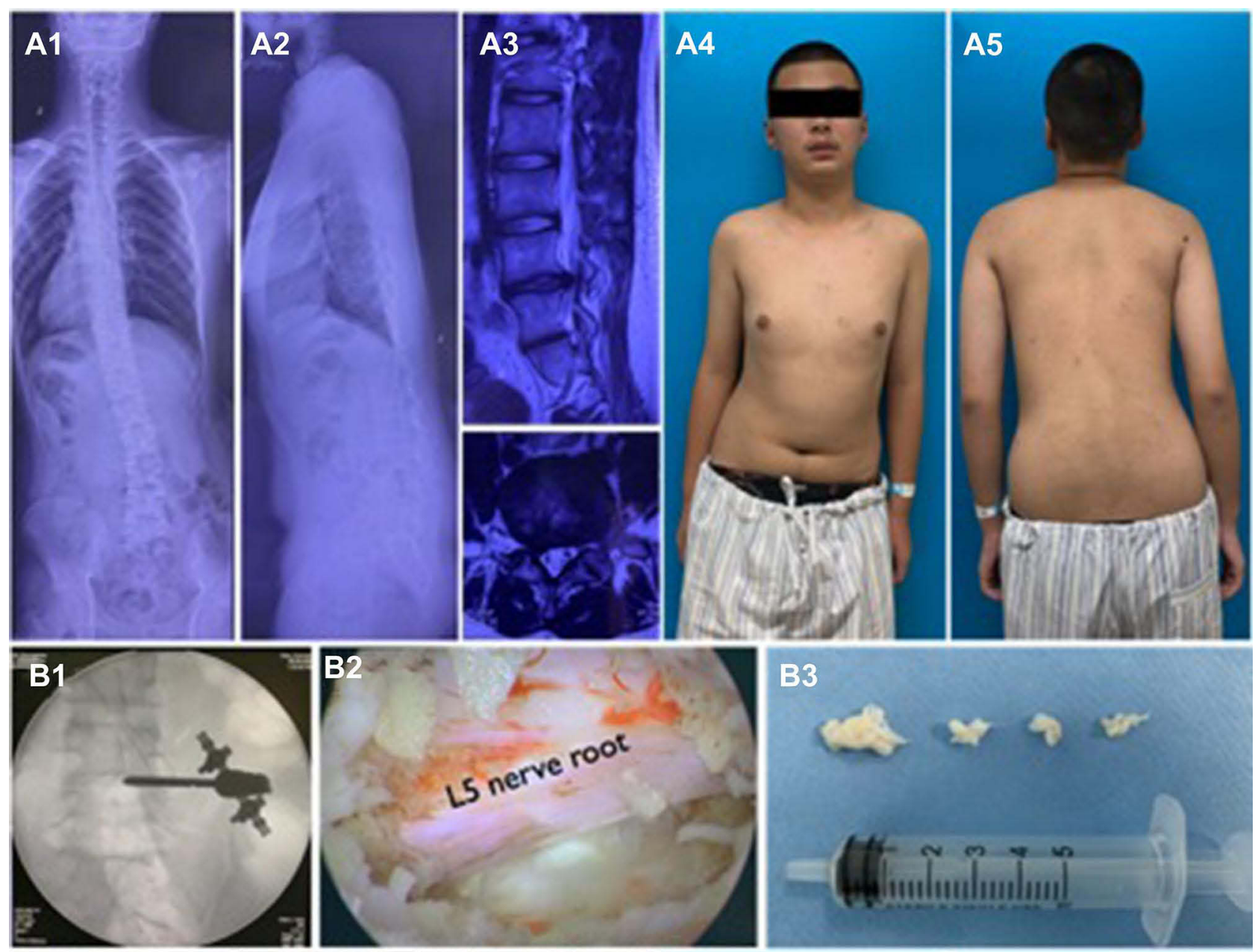

B3
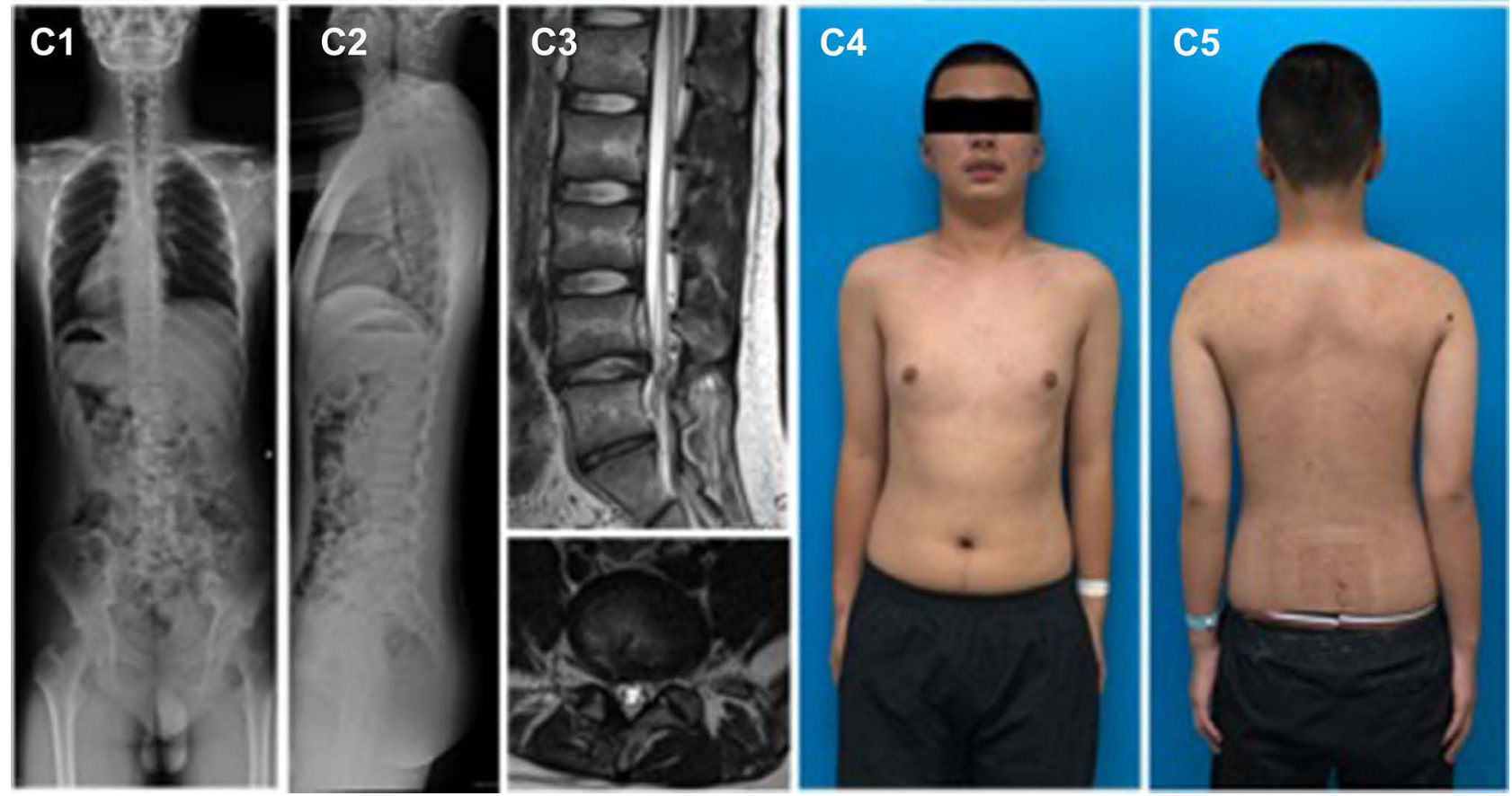

Figure 3 A 16-year-old male LDH patient with right leg sciatica present spinal sagittal and coronal imbalance (AI-2). L4/5 right side disc herniation was shown in MRI (A3). X-ray (AI-2) and physical appearance (A4-5) showed the trunk shifted to left side in coronal plane and forward in sagittal plane. UBED surgery was performed (BI-B3) and postoperative MRI showed herniated disc was removed (C3). X-ray (CI-2) and physical appearance (C4-5) showed coronal and sagittal imbalance acquired recovery immediately after surgery. 

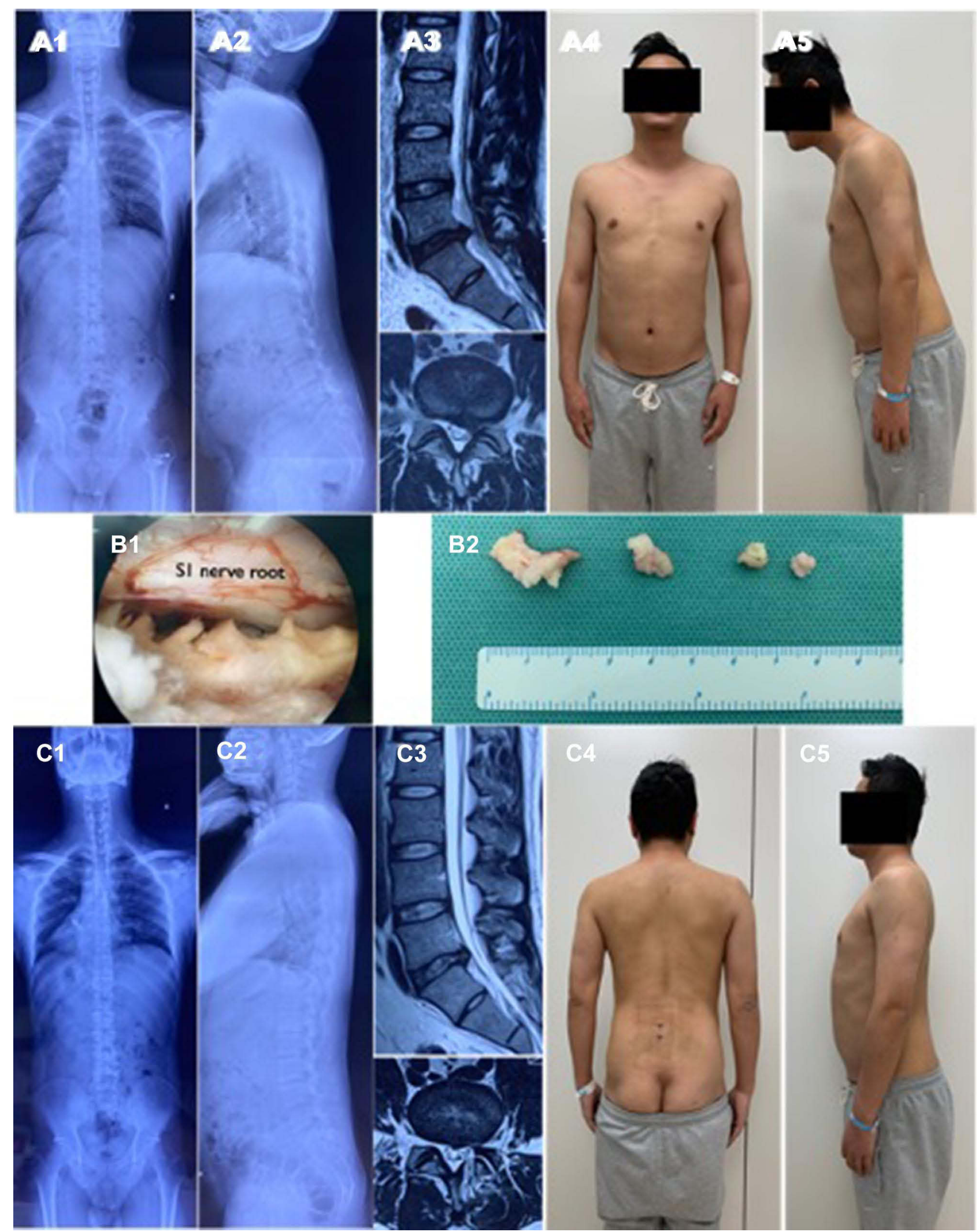

Figure 4 A 30-year-old male LDH patient with right leg sciatica present spinal sagittal imbalance (AI-2). L5/SI left side disc herniation was shown in MRI (A3). X-ray (A I-2) and physical appearance (A4-5) showed the trunk shifted to forward in sagittal plane. UBED surgery was performed (B I-B2) and postoperative MRI showed herniated disc was removed (C3). X-ray (CI-2) and physical appearance (C4-5) showed sagittal imbalance acquired recovery immediately after surgery. 


\section{Discussion}

Spinal coronal and sagittal imbalance, or named sciatic scoliosis or trunk list, have been observed in LDH patients. The abnormal trunk posture has been regarded as secondary to lumbar nerve root compression by herniated disc. ${ }^{11,14}$ In the current study, we retrospectively analyzed the spinal coronal and sagittal imbalance in 110 LDH with sciatica patients and divided them into three different subgroups to summarize the different characteristics. In addition, the improvement of spinal imbalance after surgery has been the focus of attention of spinal surgeons and patients. We also summarized the recovery process of coronal and sagittal imbalance after surgery.

There was a significant association between the side of the disc herniation and the direction of coronal trunk shift. In our study, $77.2 \%$ of the LDH patients with coronal imbalance present trunk shifted to the contralateral side of disc herniation, which was consistent with previous reports. Suk et $\mathrm{al}^{15}$ and Zhu et $\mathrm{al}^{16}$ found that $75 \%$ and $84.6 \%$ of the patients had a disc herniation at the convex side of scoliosis, respectively. Zhu et al, ${ }^{16} \mathrm{Kim}_{\text {et }} \mathrm{al}^{17}$ and $\mathrm{Wu}$ et $\mathrm{al}^{2}$ reported the trunk shifted to the contralateral side of the disc herniation in $73.1 \%, 76 \%$ and $50 \%$ patients, respectively. It remains unclear for the detailed mechanisms for the phenomenon. Finneson et $\mathrm{al}^{18}$ proposed the theory that the direction of scoliotic posture correlated with the location of herniated disc. If the herniation is located medial to the nerve root, the scoliotic posture would be towards the side of sciatica, and if the herniation is lateral to the nerve root, the scoliotic posture would go towards the opposite side. Takahashi et $\mathrm{al}^{14}$ reported that the magnitude of the nerve root pressure was higher in patients with trunk list. However, Suk et $\mathrm{al}^{15}$ reported the direction of sciatic scoliosis was not observed to be associated with the location and degree of nerve root compression.

Sagittal balance is a state in which an individual is capable of keeping a stable standing position with minimal muscle expenditure. ${ }^{8}$ In the current study, we also found that $65.3 \%$ of the patients with sagittal imbalance present with trunk shifted forward. More patients presented with trunk forward imbalance in Group $\mathrm{C}$ than Group B. Zhu et al $^{16}$ found that LDH patients with scoliotic posture showed a relatively straight sagittal profile. The changes of lumbosacral parameters could also be observed in LDH patients and compensatory mechanisms of spinal sagittal imbalance mainly include more forward translation of SVA, LL loss, TK and PT increase. ${ }^{2,8,16,17,19,20}$
In the current study, the magnitude of spinal imbalance was different among the three subgroups. The magnitude of sagittal and coronal imbalance in Group C was significantly more severe than that of Group A and Group B. According to the grading of imbalance, most patients were accompanied by mild and moderate coronal and sagittal imbalance. As for the spinal imbalance in LDH, different studies reported different results. In 2001, Suk et $\mathrm{al}^{15}$ performed a prospective study to analyze the lumbosacral scoliotic list in 45 patients with LDH. The preoperative distance of L1-CSVL was $16.7 \mathrm{~mm}$. In 2010, Endo et al $^{19}$ performed a retrospective cross-sectional study and found the mean SVA of the LDH group (32.7 $\pm 46.5 \mathrm{~mm}$ ) was significantly larger than that of the control $(2.5 \pm 17.1 \mathrm{~mm})$. In 2011, Zhu et $\mathrm{al}^{16}$ analyzed the curve pattern in 26 adolescent LDH patients with scoliotic posture. The mean trunk shift was $3.7 \mathrm{~cm}$ and $88.5 \%$ patients had a poor coronal balance with trunk shift $>2.0 \mathrm{~cm}$. In 2015 , Kim et $\mathrm{al}^{17}$ retrospectively analyzed the incidence and risk factors for sciatic scoliosis in $164 \mathrm{LDH}$ patients. Trunk shift $(>10 \mathrm{~mm})$ was observed in $18 \%$ of the patients at the time of surgery. The mean CSVA-C7PL and SVA value was $22.5 \mathrm{~mm}$ and $30.0 \mathrm{~mm}$, respectively. In 2016, Chen et $\mathrm{al}^{8}$ analyzed the spinal sagittal imbalance in 25 adult LDH patients and revealed the mean SVA and coronal trunk shift values were $11.6 \mathrm{~cm}$ and $2.9 \mathrm{~cm}$ respectively. In 2019, Wu et al ${ }^{2}$ analyzed the coronal and sagittal spinal alignment in $68 \mathrm{LDH}$ patients with scoliosis and trunk shift and found that $29.4 \%$ of the patients showed a poor coronal balance (trunk shift $>2.0 \mathrm{~cm}$ ) with the mean trunk shift of $2.6 \mathrm{~cm}$.

As for the risk factors for the spinal imbalance in LDH with sciatica patients, there were just several reports. Kim et $\mathrm{al}^{17}$ reported L4-5 disc herniation was a risk factor for trunk shift. Because L4-5 was not confined to the pelvic cavity, it may be more vulnerable to trunk list compared with L5-S1. As for whether the gender is the risk factor for the trunk shift in LDH, sciatic scoliosis was more frequently observed in men ${ }^{2,7}$ than in women ${ }^{17}$ in previous reports. In our study, the gender and affected level were not found to be related to spinal imbalance. Suk et al ${ }^{15}$ reported that age, gender, side, anatomic location, and degree of herniation, and direction of scoliosis did not have an effect on the degree of scoliosis and trunk shift.

As the nonstructural and protective scoliotic posture, coronal and sagittal spinal imbalance would be improved once the nerve root decompression was achieved. In our study, most of the patients ( $\geq 75 \%$ ) acquired spinal balance 
immediately after surgery. The sagittal imbalance improved better than coronal imbalance and single plane imbalance improved better than biplane imbalance. At postoperative 6-month follow-up, all patients recovered to normal sagittal and coronal balance. As for the recovery, previous studies had similar results but with some differences. Suk et $\mathrm{al}^{15}$ reported most of the sciatic scoliotic list disappeared after surgical decompression. Zhu et al $^{16}$ reported all of the patients had a marked coronal scoliosis improvement immediately after discectomy. Immediately after surgery, the mean thoracic or thoracolumbar curve decreased from $24.7^{\circ}$ to $10.4^{\circ}$, and the mean trunk shift decreased from $3.7 \mathrm{~cm}$ to $1.2 \mathrm{~cm}$. Chen et $\mathrm{al}^{8}$ reported that all patients restored coronal and sagittal balance immediately after lumbar discectomy. The mean C7PL-SVA and trunk shift value decreased from $(11.6 \pm 6.6 \mathrm{~cm}$ and $2.9 \pm 6.1 \mathrm{~cm})$ preoperatively to $(-0.5 \pm 2.6 \mathrm{~cm}$ and $0.2 \pm 0.5 \mathrm{~cm})$ postoperatively. Tu et $\mathrm{al}^{21}$ reported that all the adolescent LDH patients with sciatic scoliosis have a curve improvement after full-endoscopic interlaminar discectomy. Zhang et $\mathrm{al}^{22}$ reported that a total of $85.7 \%$ of the adolescent and $92.7 \%$ of the adult patients with sciatic scoliosis achieved resolution of scoliosis within 6 months after surgery. Kim et al ${ }^{17}$ revealed that trunk list was reversible in more than $50 \%$ of the patients within 6 months of PELD. Matsui et $\mathrm{al}^{7}$ reported that sciatic scoliotic list completely disappeared in $45 \%$ patients and the average time was 107 days after surgery. Endo et al ${ }^{19}$ revealed that the sagittal malalignment recovered to almost the same level as the control group at 6 months after surgery. In all, the coronal and sagittal imbalance could be achieved favorable recovery results immediately after surgery and during follow-up.

As for the spinal coronal and sagittal imbalance, the detailed mechanisms remain unclear. It has been widely accepted that the abnormal posture is compensatory behavior of the body to ease the stimulation of nerve roots and relieve the sciatica symptom. The radiological features of sciatic trunk shift were different from idiopathic scoliosis. There was no vertebral wedging in the apical area and just limited vertebral rotation. ${ }^{16}$ Careful clinical and radiological assessment is crucial to different spinal imbalance in LDH from other structural spinal deformity and adopt appropriate management.

There were some limitations for the current study. It was a retrospective study with limited case numbers. The study just focused on the LDH and sciatica patients receiving endoscopic discectomy surgery and nonsurgical patients with spinal imbalance were not included, which may cause some bias for the results. In addition, it remained unknown as for the detailed reasons and mechanisms for the different characteristics of different subgroups in the current study. More multi-center clinical cohort studies with large sample size are needed to better analyze the spinal imbalance in LDH patients.

\section{Conclusion}

Spinal imbalance was not uncommon in LDH with sciatica patients, and the incidence rate was $18.3 \%$ among the patients receiving endoscopic discectomy surgery. Most patients accompanied with mild and moderate coronal and sagittal imbalance. Different spinal imbalance types present with different characteristics. The magnitude of sagittal and coronal imbalance in biplane imbalance group was significantly more severe than that of monoplane imbalance. Spontaneous correction of the spinal imbalance could be achieved when sciatica was relieved immediately after surgery and well maintained during follow-up.

\section{Ethics Statement}

This study was approved by the ethics committee of Qilu Hospital of Shandong University (No. KYLL-2019KS058). The study was performed in accordance with the principles of the Helsinki Declaration of 1964 and its later amendments. All patients provided informed consent for participation in the study and research publication.

\section{Funding}

This work was supported by the National Natural Science Foundation of China (No. 81902276) and the Key R \& D project of Shandong Province of China (No. 2019GSF108032).

\section{Disclosure}

The authors report no conflicts of interest in this work.

\section{References}

1. Benzakour T, Igoumenou V, Mavrogenis AF, Benzakour A. Current concepts for lumbar disc herniation. Int Orthop. 2019;43:841-851. doi:10.1007/s00264-018-4247-6

2. Wu W, Chen Y, Yu L, Li F, Guo W. Coronal and sagittal spinal alignment in lumbar disc herniation with scoliosis and trunk shift. J Orthop Surg Res. 2019;14:264. doi:10.1186/s13018-019-1300-0

3. Truumees E. A history of lumbar disc herniation from Hippocrates to the 1990s. Clin Orthop Relat Res. 2015;473:1885-1895. doi:10.1007/ s11999-014-3633-7

4. Falavigna A, Scheverin N, Righesso O, et al. Economic value of treating lumbar disc herniation in Brazil. J Neurosurg Spine. 2016;24:608-614. doi:10.3171/2015.7.SPINE15441 
5. Matsuyama Y, Chiba K, Iwata H, Seo T, Toyama Y. A multicenter, randomized, double-blind, dose-finding study of condoliase in patients with lumbar disc herniation. $J$ Neurosurg Spine. 2018;28:499-511. doi:10.3171/2017.7.SPINE161327

6. Konstantinou K, Dunn KM. Sciatica: review of epidemiological studies and prevalence estimates. Spine (Phila Pa 1976). 2008;33:2464-2472. doi:10.1097/BRS.0b013e318183a4a2

7. Matsui H, Ohmori K, Kanamori M, Ishihara H, Tsuji H. Significance of sciatic scoliotic list in operated patients with lumbar disc herniation. Spine (Phila Pa 1976). 1998;23:338-342. doi:10.1097/ 00007632-199802010-00010

8. Liang C, Sun J, Cui X, Jiang Z, Zhang W, Li T. Spinal sagittal imbalance in patients with lumbar disc herniation: its spinopelvic characteristics, strength changes of the spinal musculature and natural history after lumbar discectomy. BMC Musculoskelet Disord. 2016;17:305. doi:10.1186/s12891-016-1164-y

9. Kleinberg S. Sciatic scoliosis. Am J Surg. 1950;80:332-337. doi:10.1016/0002-9610(50)90507-1

10. Krishnan KM, Newey ML. Lumbar scoliosis associated with a disc herniation in an adult. Rheumatology (Oxford). 2001;40:1427-1428. doi:10.1093/rheumatology/40.12.1427

11. Gillan MG, Ross JC, McLean IP, Porter RW. The natural history of trunk list, its associated disability and the influence of McKenzie management. Eur Spine J. 1998;7:480-483. doi:10.1007/ s005860050111

12. Ferrero E, Liabaud B, Challier V, et al. Role of pelvic translation and lower-extremity compensation to maintain gravity line position in spinal deformity. J Neurosurg Spine. 2016;24:436-446. doi:10.3171/ 2015.5.SPINE14989

13. Shin EK, Kim CH, Chung CK, et al. Sagittal imbalance in patients with lumbar spinal stenosis and outcomes after simple decompression surgery. Spine J. 2017;17:175-182. doi:10.1016/j.spinee.2016.08.023
14. Takahashi K, Shima I, Porter RW. Nerve root pressure in lumbar disc herniation. Spine (Phila Pa 1976). 1999;24:2003-2006. doi:10.1097/ 00007632-199910010-00007

15. Suk KS, Lee HM, Moon SH, Kim NH. Lumbosacral scoliotic list by lumbar disc herniation. Spine (Phila Pa 1976). 2001;26:667-671. doi:10.1097/00007632-200103150-00023

16. Zhu Z, Zhao Q, Wang B, et al. Scoliotic posture as the initial symptom in adolescents with lumbar disc herniation: its curve pattern and natural history after lumbar discectomy. BMC Musculoskelet Disord. 2011;12:216. doi:10.1186/1471-2474-12-216

17. Kim R, Kim RH, Kim CH, et al. The incidence and risk factors for lumbar or sciatic scoliosis in lumbar disc herniation and the outcomes after percutaneous endoscopic discectomy. Pain Physician. 2015;18:555-564. doi:10.36076/ppj.2015/18/555

18. Finneson BE. Psychosocial considerations in low back pain: the "cause" and "cure" of industry related low back pain. Orthop Clin North Am. 1977;8:23-26. doi:10.1016/S0030-5898(20)30931-7

19. Endo K, Suzuki H, Tanaka H, Kang Y, Yamamoto K. Sagittal spinal alignment in patients with lumbar disc herniation. Eur Spine J. 2010;19:435-438. doi:10.1007/s00586-009-1240-1

20. Rajnics P, Templier A, Skalli W, Lavaste F, Illes T. The importance of spinopelvic parameters in patients with lumbar disc lesions. Int Orthop. 2002;26:104-108. doi:10.1007/s00264-001-0317-1

21. Tu Z, Wang B, Li L, et al. Early experience of full-endoscopic interlaminar discectomy for adolescent lumbar disc herniation with sciatic scoliosis. Pain Physician. 2018;21:E63-63E70.

22. Zhang Y, Li W, Xu L, Jiang E, Qiu Y, Zhu Z. Sciatic scoliosis evolution after lumbar discectomy: a comparison between adolescents and young adults. Pain Physician. 2019;22:E457-457E465.
Journal of Pain Research

\section{Publish your work in this journal}

The Journal of Pain Research is an international, peer reviewed, open access, online journal that welcomes laboratory and clinical findings in the fields of pain research and the prevention and management of pain. Original research, reviews, symposium reports, hypothesis formation and commentaries are all considered for publication. The manuscript management system is completely online and includes a very quick and fair peer-review system, which is all easy to use. Visit http:// www.dovepress.com/testimonials.php to read real quotes from published authors. 